\title{
ANÁLISE DO REVESTIMENTO METÁLICO APLICADO EM MATRIZ DE CONFORMAÇÃO DE ELEMENTOS DE FIXAÇÃO EM AÇOS INOX AUSTENÍTICOS
}

\author{
José Mario Fernandes De Paiva Junior ${ }^{1}$
}

Nichelly Katiúcia Dias²

\section{RESUMO}

Este trabalho tem como objetivo testar a aplicação de um revestimento metálico, depositado em matrizes de conformação, para a fabricação de parafusos em aços Inox Austeniticos $302 \mathrm{HQ}$. Um dos problemas que ocorrem durante o processo de conformação é a adesão do material conformado, o Aço Inox $302 \mathrm{HQ}$ na matriz de conformação revestida com TiCN (Carbonitreto de Titânio). O revestimento metálico testado, foi o Nitreto de Titânio Alumínio o TiAIN. As matrizes de conformação passaram pelos seguintes processos: usinagem, polimento para reduzir a rugosidade, nitretação e revestimento com TiAIN.Para analisar o comportamento do novo revestimento, foram utilizados os seguintes testes: análise de integridade superficial através da rugosidade; ensaios de caracterização microestrutural por MEV (Microscopia Eletrônica de Varredura); ensaio de adesividade do revestimento; testes de estampagem; análise metalográfica nas linhas de deformação de um parafuso conformado pela primeira matriz testada. Determinou-se que as matrizes devem apresentar um padrão de rugosidade superficial, para evitar o desgaste e melhorar o processo. No processo de conformação é fundamental que não tenha falhas. Uma variável que deve ser controlada é o alinhamento entre a ferramenta e o blank. A ferramenta revestida pelo processo de PVD, com TiAIN apresentou produtividade considerável, adequando-se ao processo.

Palavras-chave: Revestimentos. Nitreto de Titânio Alumínio.Conformação.

\footnotetext{
${ }^{1}$ Mestre, e-mail: josemario@sc.senai.br

${ }^{2}$ Tecnóloga, e-mail: nichelly.dias@sc.senai.br
} 


\section{INTRODUÇÃO}

Com a ampla utilização de elementos de fixação (parafusos, porcas, arruelas, etc.), as indústrias têm a necessidade de buscar novas pesquisas que visam o aumento da produtividade. A utilização de matrizes de conformação com superfícies revestidas, contribui para o aumento na eficiência dos processos produtivos, refletindo no aumento da vida das ferramentas, no menor número de setups e na redução da ocorrência de falhas e paradas indesejadas da produção.

As indústrias do setor metal-mecânico utilizam técnicas de modificação das superfícies de ferramentas de conformação mecânica sujeitas ao desgaste, em função do processo e meio em que trabalham. Considerando as inúmeras alternativas de tecnologias disponíveis, a tecnologia de deposição de revestimentos pelo processo de PVD (Deposição Física por Vapor) se torna cada vez mais empregada em ferramentas de conformação para a redução de desgaste e conseqüente aumento de vida útil das mesmas (KALPAKJIAN; SCHMID, 2008). Os tratamentos de superfícies com revestimentos desenvolvidos pelo processo PVD, contribuem para a diminuição do coeficiente de atrito, o que possibilita um acréscimo no desempenho da matriz utilizada no processo de conformação (PESCH et al., 2003).

Atualmente, o principal problema durante a fabricação dos elementos de fixação é a formação de trincas na região da borda da cabeça dos parafusos (figura 1), isso eleva a taxa de sucateamento do processo. E também pode reduzir a qualidade do produto, tanto na aparência, quanto em suas propriedades mecânicas. (DE PAULA, 2010).

Figura 1: Vista superior de parafuso de cabeça redonda flangeada com fenda Phillips, ilustrando as trincas

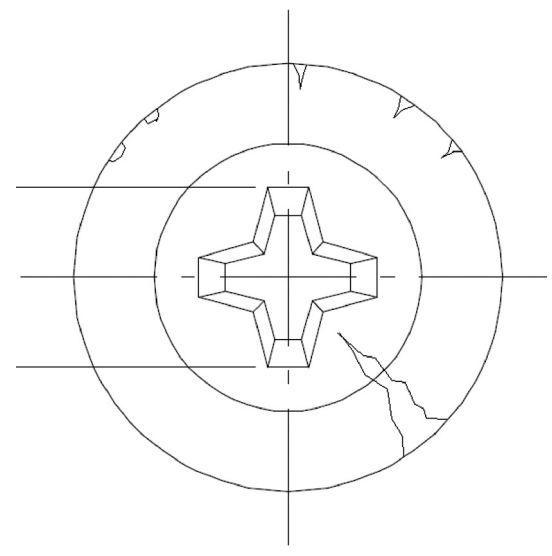

Fonte: De Paula (2010)

Observam-se diferentes problemas na fabricação de parafusos de aço inoxidável AISI 302HQ:

a) queda de rendimento do ferramental; 
b) aderência de material nas matrizes de conformação;

c) sujeira excessiva na máquina;

d) quebra de punções de conformação de fenda Phillips.

De acordo com De Paula (2010), a frequência da ocorrência de trincas nos parafusos é aleatória, e a inspeção é feita por sub-lotes: ela é realizada assim que os parafusos encham o recipiente menor. Uma grande quantidade de parafusos é rejeitada, tornandose refugo, consequentemente, o tempo gasto para produzir determinada quantidade de parafusos nesse processo é maior do que deveria ser, pois boa parte desse tempo é gasto na fabricação de produtos defeituosos, e na produção de refugo. Além disso, assim que é detectada a ocorrência de trincas, o operador pára a máquina e toma providências, portanto, o problema das trincas acarreta o aumento de tempo no processo.

As matrizes de conformação foram fabricadas em empresa do setor, pelo processo de usinagem CNC e eletro-erosão. Em seguida passaram por um processo de polimento a fim de melhorar as propriedades da superfície. Antes de revestir as matrizes, estas passaram pelo tratamento térmico de nitretação.

Após a nitretação as matrizes foram revestidas com TiAIN (Nitreto de Aluminio e Titânio). A tabela 1 mostra a descrição das principais características dos revestimentos atual TiCN e o novo TiAIN.

Tabela 1: Principais características dos revestimentos - Adaptação Oerlikon Balzers

\begin{tabular}{|l|l|l|l|l|l|}
\hline $\begin{array}{l}\text { Material do } \\
\text { Revestimento }\end{array}$ & $\begin{array}{l}\text { Microdureza } \\
\text { HV }\end{array}$ & $\begin{array}{l}\text { Coeficiente } \\
\text { de atrito }\end{array}$ & $\begin{array}{l}\text { Temperatura } \\
{ }^{\circ} \mathbf{C}\end{array}$ & $\begin{array}{l}\text { Espessura } \\
\text { Max. } \mathbf{m}\end{array}$ & Cor \\
\hline TiAIN & 3300 & $0,30-0,35$ & 900 & 3 & $\begin{array}{l}\text { cinza } \\
\text { violeta }\end{array}$ \\
TiCN (atual) & 3000 & 0,4 & 400 & 4 & $\begin{array}{l}\text { azul- } \\
\text { acinzentado }\end{array}$ \\
\hline
\end{tabular}

Fonte: Oerlikon Balzers ([2010])

Por apresentar um coeficiente de atrito um pouco menor que o revestimento atual, o TiAIN obteve melhor destaque neste estudo.

O presente trabalho pretende analisar o desempenho do revestimento metálico TiAIN depositado em matrizes de conformação a frio, usadas na fabricação de elementos de fixação em aços Inox Austeniticos. Alguns objetivos específicos foram traçados: definir padrões de acabamento superficial da matriz de conformação, para consequentemente, depositar revestimentos metálicos; identificar mecanismos de falha ao longo do processo produtivo. 


\section{MÉTODOS}

O desenvolvimento deste estudo consiste em, inicialmente através de análise de integridade superficial das ferramentas, identificar a topografia da superfície e suas propriedades de adesão mecânica. Através dessa análise será possível avaliar os parâmetros que influenciam as condições ideais para adesividade do revestimento sobre determinada matriz de conformação para a fabricação de elementos de fixação.

As atividades de ensaios técnicos e análise de resultados serão distribuídas da seguinte maneira:

a) Ensaios de caracterização microestrutural por Microscopia Eletrônica de Varredura (MEV):

b) Avaliar o grau de acabamento das ferramentas revestidas;

c) Caracterização microestrutural do aço ferramenta.

O ensaio de adesividade do revestimento em relação à camada superficial ao substrato será desenvolvido com o intuito de definir o bom desempenho de adesão do revestimento. Já, para testes de estampagem foi disponibilizado uma prensa hidráulica $2 \mathrm{~T}$ na unidade fabril da empresa parceira deste estudo.

\section{RESULTADOS OBTIDOS}

As matrizes de conformação (figura 2) foram fabricadas pela empresa parceira deste projeto, em aço AISI D6, conforme especificação do American Institute of Steel and Iron (AISI). Após a usinagem foram medidas a rugosidade das matrizes, e depois polidas. Posteriormente, as matrizes foram encaminhadas para tratamento termoquímico nitretação e revestidas com filme fino TiAIN (Nitreto de Tiânio e Alumínio).

Figura 2: Vista superior da matriz de conformação de elementos de fixação

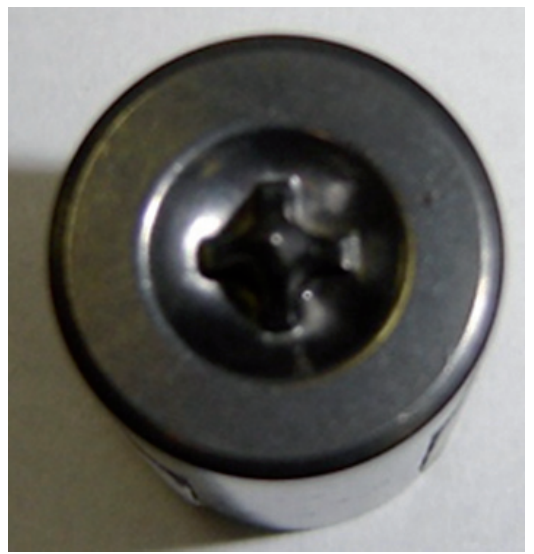

Fonte: Dos autores (2011) 
Foram medidas as rugosidades das matrizes, antes de passar pela nitretação, como a rugosidade se encontrava muito alta, as matrizes foram polidas mais de uma vez, a tabela 2 mostra a média das rugosidades das matrizes.

Tabela 2: Média da rugosidade das matrizes

\begin{tabular}{l|l}
\hline sem polimento & $\mathbf{0 , 1 1} \boldsymbol{\mu m}$ \\
\hline 1o polimento & $0,052 \mu \mathrm{m}$ \\
\hline o polimento & $0,045 \mu \mathrm{m}$ \\
\hline
\end{tabular}

Fonte: Dos autores (2011)

Devido ao processo de usinagem, as matrizes apresentavam uma rugosidade inadequada, para serem nitretadas, portanto, foram encaminhadas para o processo de polimento.

\subsection{Microscopia Eletrônica de Varredura (MEV)}

O objetivo desta etapa serve para avaliar o grau de acabamento das matrizes revestidas e se apresentam falhas no revestimento através da Microscopia Eletrônica de Varredura (MEV). Foram feitas micrografias da ferramenta nova revestida com TiAIN (figura 3) e da revestida com TiC (figura 4).

Figura 3: Vista do topo Ferramenta Revestida com TiAlN. Ampliação 20x

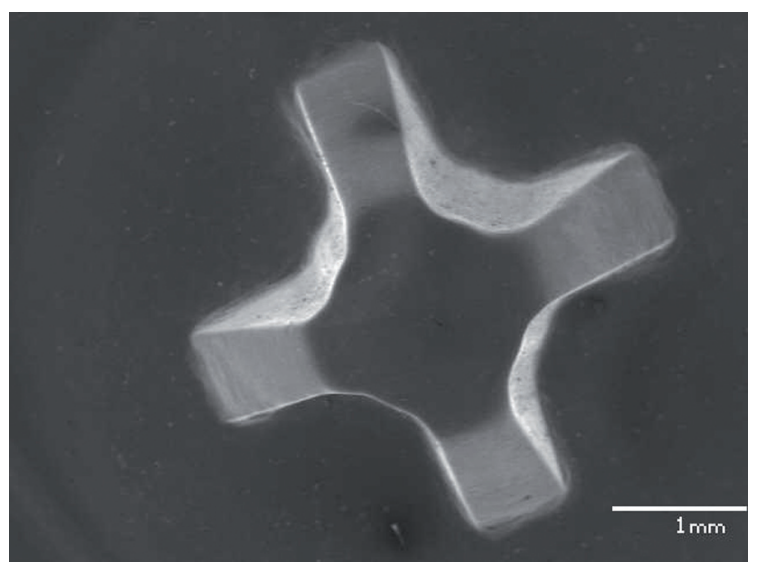

Fonte: Dos autores (2011) 


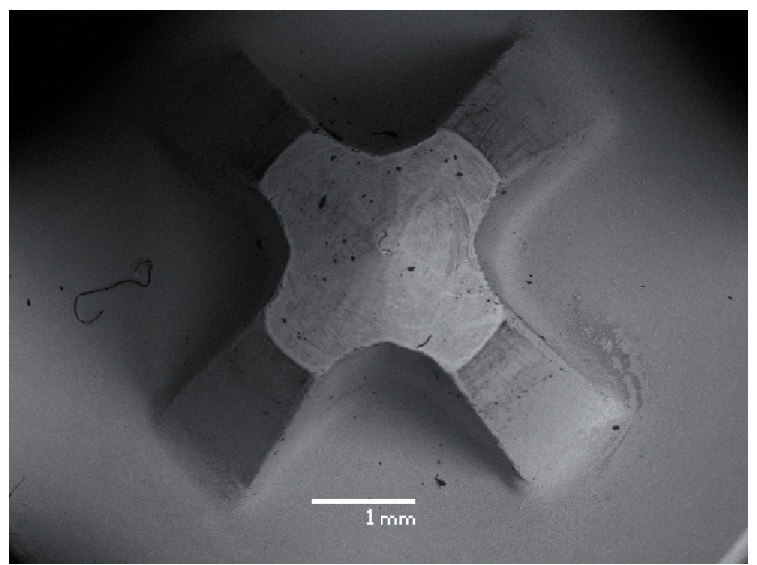

Fonte: De Paula (2010 apud PUC-PR, 2010)

Comparando os dois resultados de micrografias (fig. 3 e 4), a figura 4, que apresenta a matriz revestida com TiC, mostra a distribuição não-uniforme do revestimento devido ao processo de aplicação. Observando a figura 3 da matriz revestida com TiAIN, observase a boa distribuição do revestimento formando uma camada uniforme ao longo da topografia da matriz.

\subsection{Adesividade do revestimento}

O objetivo deste ensaio é avaliar a adesividade dos revestimentos depositados sobre os substratos. $O$ ensaio consiste em indentar o conjunto revestimento/substrato através de um ensaio de dureza. (FONSECA; MACHADO, 2006)

Bhushan (1991, apud KÖNIG, 2007), descreve que a adesividade das camadas de revestimento ao substrato são avaliadas através do método de indentação. A análise na matriz sem uso mostra o surgimento de trincas radiais e longitudinais. Entretanto, a amostra ainda apresentou boa adesão segundo o padrão escolhido como referência

Para avaliar a adesão entre o substrato e o filme revestido foram usados os padrões HF figura 5. As identações foram realizadas no equipamento Wilson Rockell, a carga utilizada foi de $150 \mathrm{kgf}$ e o penetrador foi um cone de diamante 
Figura 5: Padrões HF para adesão de revestimentos

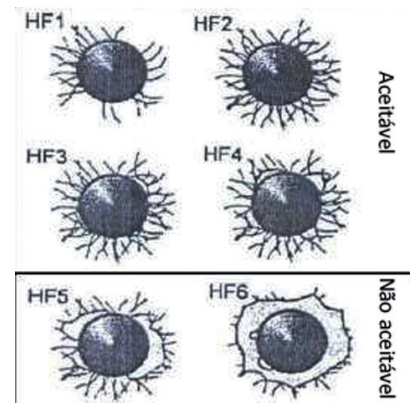

Fonte: Heinke (1995, apud KÖNIG, 2007)

Para comparar as indentações feitas na matriz revestida com TiAIN, utilizou-se a indentação feita pela PUC-PR (2010, apud DE PAULA, 2010) da matriz revestida com TiC na figura 6.

Figura 6: Indentação HRC Ferramenta Revestida com TiC; B - Indentação HRC Ferramenta Revestida com TiAIN
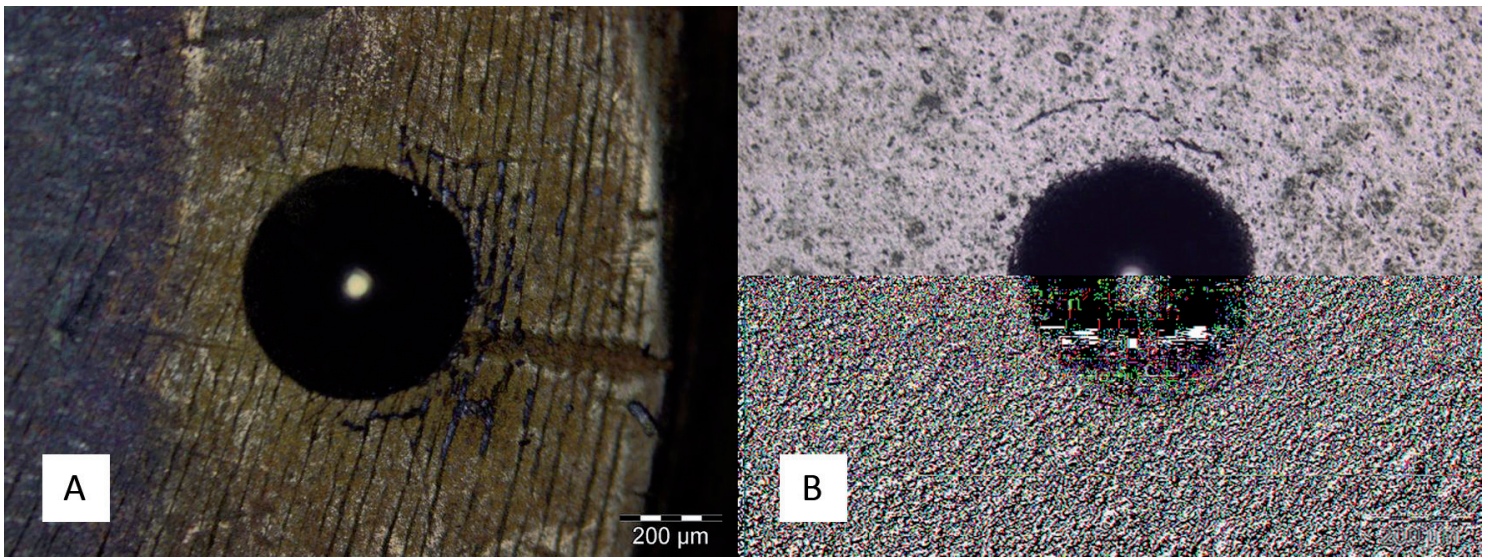

Fonte: Dos autores (2011)

A figura 6A mostra a matriz revestida com TiCN evidenciada pelas trincas ao redor da indentação, a má adesão do revestimento no substrado da matriz, podendo analisar também o péssimo acabamento da matriz. A figura 6B mostra a Indentação realizada na ferramenta revestida com TiAIN. Observa-se que ocorrem poucas trincas radiais não influenciando na adesão do material no substrato. Da mesma forma, observa-se na figura o bom acabamento do revestimento na matriz.

Como já foi visto na figura 6B, a amostra apresenta uma superfície com uma rugosidade superficial adequada. Ou seja, a importância da preparação da amostra, está relacionada à textura da superfície final, onde o revestimento depositado sobre a superfície acompanha o relevo apresentado. Superfícies com parâmetros de rugosidade elevada apresentam fragilidade na adesão do revestimento, propagando as solicitações de forma mais fácil. 


\subsection{Teste de estampagem}

Três matrizes revestidas com TiAIN foram levadas para testes de estampagem. Para analisar a vida útil da matriz quanto ao processo, parafusos foram selecionados e analisados. A primeira matriz confeccionou 1400 parafusos até parar por quebra, foram coletadas amostras no final do processo. A segunda matriz confeccionou 2210 parafusos até parar por quebra. Amostras foram coletadas no início do processo, nos primeiros 15 minutos de operação e aos 30 minutos de operação. A terceira matriz confeccionou 3700 peças e atingiu o limite de desgaste pré-estabelecido pela fabricante de parafusos.

\subsection{Micrografia óptica}

Durante o processo de conformação do parafuso foram recolhidas amostras para fazer micrografias. Na análise das linhas de deformação, como pode-se observar na figura 7, as linhas estão bem distribuídas em ambos os lados.

Figura 7: Perfil de parafuso confeccionado com matriz revestida com TiAIN, ampliação em 50x

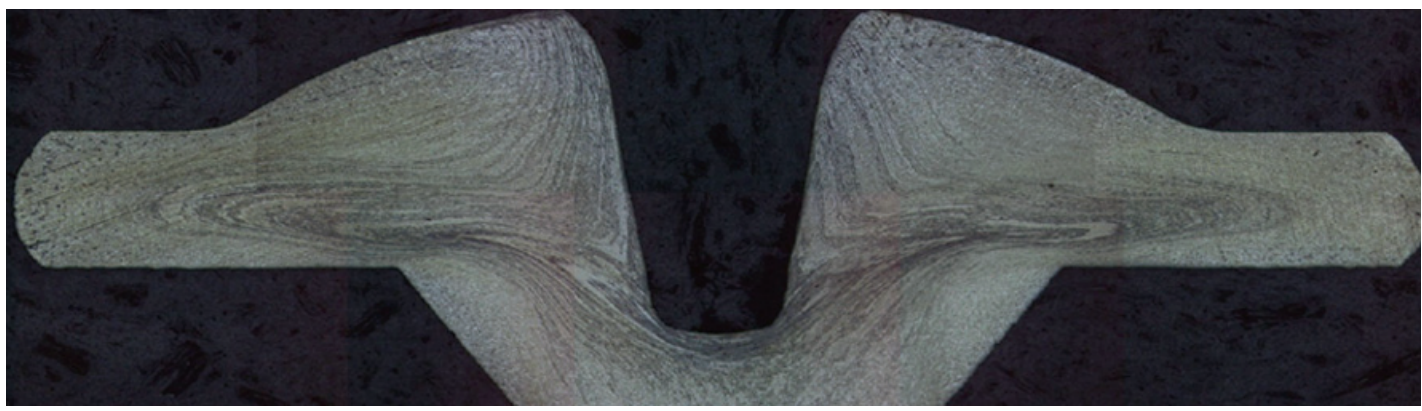

Fonte: Dos autores

Pode-se comparar as micrografias do parafuso conformado pela matriz revestida com TiAIN. A figura 8 mostra uma micrografia de parafuso conformado pela matriz revestida com TiCN.

Figura 8: Montagem das micrografias do segundo estágio de conformação - Ataque Marble, ampliação 50x. (a) Falha no corte

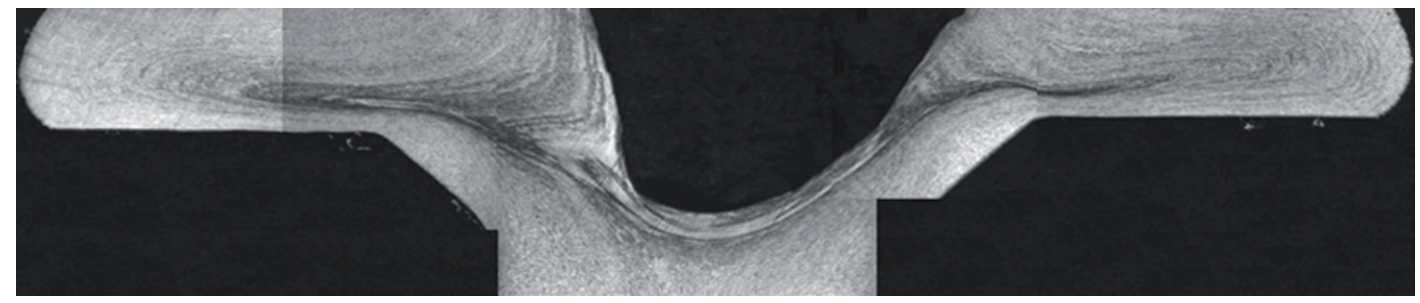

Fonte: De Paula (2010 apud PUC-PR, 2010) 
Na figura 8, observa-se o detalhe (a) uma falha no corte, e também a péssima distribuição das linhas de deformação. As micrografias dos parafusos conformados pela matriz revestida TiAIN obtiveram o melhor resultado.

\section{CONCLUSÃO}

Foi possível identificar algumas situações referentes ao bom desempenho do revestimento metálico TiAIN depositado em matrizes de conformação a frio, usadas na fabricação de elementos de fixação em aços inox austeniticos. A terceira matriz testa obteve uma boa produtividade de 3700 parafusos.

No processo de conformação, uma importante variável a ser controlada é o alinhamento entre a ferramenta e o blank da matéria prima, esse alinhamento, elimina trinca nas superfícies, bem como facilita a distribuição simétrica das linhas de conformação do produto. Essa informação foi constatada no experimento quando as duas primeiras matrizes quebraram. Observou-se o desalinhamento entre a matriz de conformação e o blank. Destaca-se neste caso a necessidade de atenção do operador, para que este erro ocorra.

Da mesma forma, ferramentas revestidas pelo Processo de PVD, com TiAIN apresentaram produtividade considerável, sendo adequados para o processo de conformação a frio de Aço Inoxidável $302 \mathrm{HQ}$. Com base neste resultado indicam-se pesquisas futuras para avaliar a matriz de conformação no processo produtivo considerando escala e tempo de produção. 


\title{
ANALYSIS OF METALLIC COATING USED IN MATRIX CONFORMATION OF FIXING ELEMENTS IN AUSTENITIC STAINLESS STEEL
}

\begin{abstract}
This study aims to test the application of a metallic coating, deposited in forming matrices, to manufacture Austenitic $302 \mathrm{HQ}$ stainless steel screws. One of the problems that occur during the forming process is the adhesion of the conformal material, the Stainless Steel $302 \mathrm{HQ}$, on the forming matrix coated with TiCN (Titanium Carbon Nitride). The metallic coating tested was Titanium Nitride Aluminium, TiAIN. The forming matrices passed through the following processes: machining, polishing to reduce roughness, nitriding and TiAIN coating. The following tests were used to analyze the behaviour of the new coating: analysis of surface integrity by roughness; microstructural characterization tests by SEM (Scanning Electron Microscopy); coating adhesion tests, embossing tests, metallographic analysis: applied to the deformation lines of a screw formed by the first tested matrix. It was determined that the matrices must have a roughness pattern to avoid wear and improve the process. In the forming process it is essential that no flaws should be present. A variable that must be controlled is the alignment between the tool and blank. The tool coated by PVD process, with TiAIN showed considerable productivity, adapting itself to the process.
\end{abstract}

Keywords: Coatings. Titanium Aluminum Nitride. Forming.

\section{REFERÊNCIAS}

OERLIKON BALZERS. Principais características dos revestimentos. [S.I.: s.n.], [2010].

Disponível em: <http://www.oerlikonbalzerscoating.com/bbr/por/01-productsservices/015-coating-guide/indexW3DnavidW261.php> Acesso em: 04 abr. 2011.

DE PAULA, J. J. S. Análise da formação de trincas durante a conformação a frio de parafusos de aço inoxidável austenítico 302HQ. 2010. Trabalho de Conclusão de Curso (Graduação CST em Fabricação Mecânica)- Faculdade de Tecnologia SENAI, Joinville, 2010.

FONSECA, Marcelo Dias da; MACHADO, A. R. Influência da texturização a laser na vida de insertos de metal duro no fresamento de ferro fundido vermicular e na adesividade do revestimento Tialn. 2006. (Apresentação de Trabalho/Congresso).

KALPAKJIAN, Serope; SCHMID, Steven R. Manufacturing processes for engineering materials. 5th ed. New Jersey: Pearson Education, 2008. 
KÖNIG, Rafael G. Estudo de desgaste de revestimentos em matrizes de recorte a frio de cabeças de parafusos. 2007.142 f. Dissertação (Mestrado em Engenharia de Materiais)

- Universidade Federal de Santa Catarina, Florianópolis, 2007.

PESCH, P. et al. Performance of hard coated steel tools for steel sheet drawing. Surface and Coatings Technolog, 163-164, No.1-3, pp.739-746, 2003.

\section{SOBRE OS AUTORES}
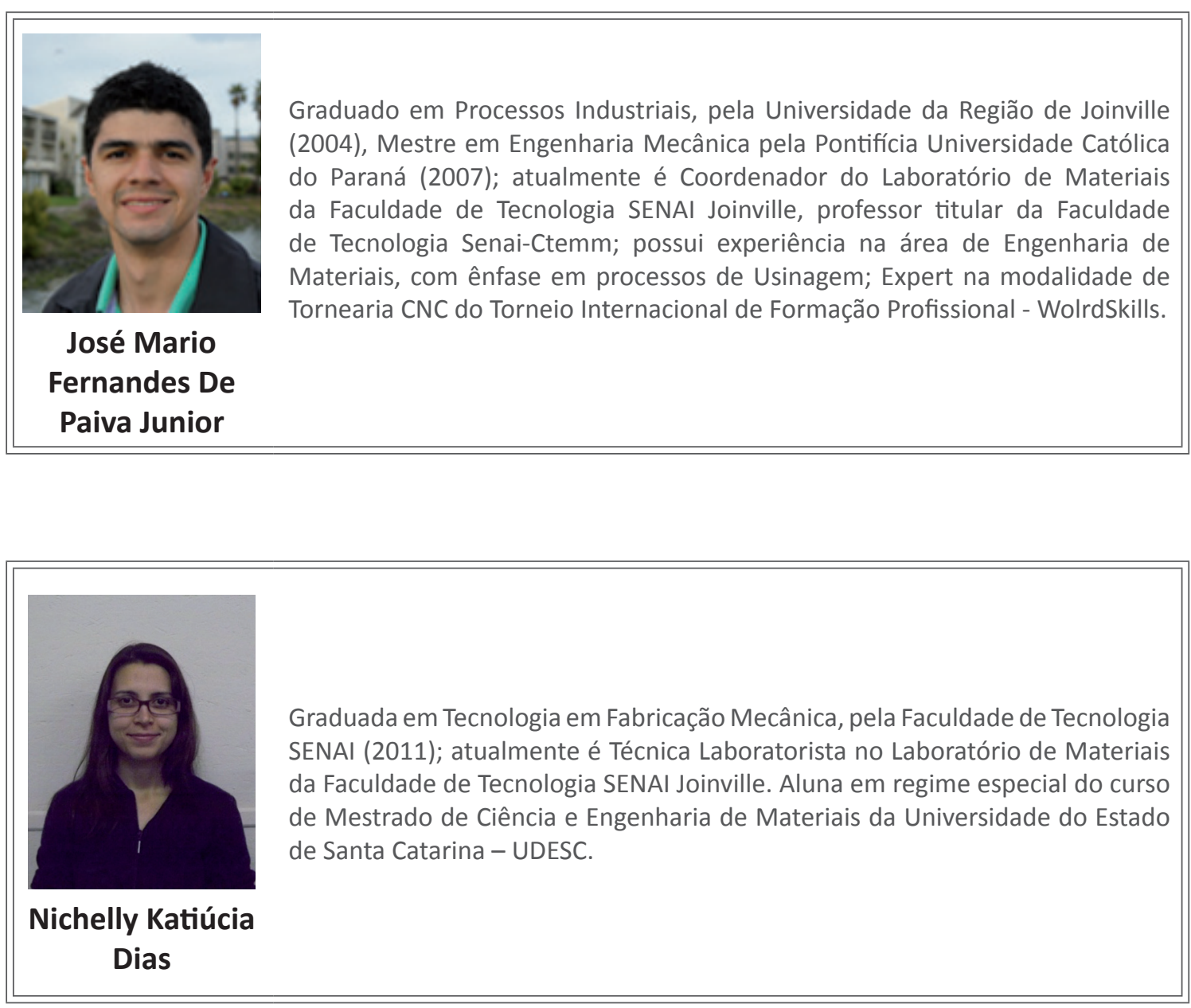